\title{
4 Fostering transformative professionalism through curriculum changes within a Bachelor of Music
}

\author{
Gemma Carey and Leah Coutts
}

\section{Introduction}

Higher music education (HME) has traditionally prepared graduates for performance/creation-based professions. Music educators and researchers have, however, recently advocated for the need to expand professionalism beyond discipline-specific knowledge and skills, to developing well rounded, socially informed graduates who can contribute to society and create meaningful and sustainable livelihoods (Bennett, 2019). As HME pedagogues and researchers Willingham and Carruthers (2018) explain,

the single-minded cultivation of personal capital that once typified conservatoire and conservatoire-like instruction - simply becoming better at playing an instrument, for example, and learning the history and theory that is a prerequisite to informed interpretation - can fall short of contemporary societal expectations and needs.

In addition to being skilled practitioners, 21 st-century musicians are required to be autonomous and agile learners (Bridgstock \& Hearn, 2012) who are socially responsible and engaged (Bartleet, \& Carfoot, 2014; Crossick, 2018) and possess strong leadership and entrepreneurial capabilities (Bennett et al., 2015).

This necessitates a shift in the conceptualisation of professionalism towards transformative professionalism (Sachs, 2003), with a focus on lifelong learning, critical engagement, collaboration, and being driven by moral and social purpose. Such an objective requires institutions to implement an innovative, transformative, and holistic approach to curriculum design and pedagogy that equips students with skills and attributes required to thrive and adapt in today's society. How then might HME achieve this objective?

\section{Expanding professionalism in HME}

While many institutions still rely on a traditional curriculum and pedagogical practices which support music students who aspire to become full-time 
performers/creators (Bennett, 2019; Tolmie, 2014), this narrow focus does not reflect the reality of graduate needs and in fact can become an impediment to graduate success. Graduates are often faced with managing "multiple concurrent roles" (Bennett, 2019, p. 4), requiring a broadening of learning opportunities that enable them to seek and create a portfolio career. Over the last decade there has been general academic consensus (e.g. Bartleet et al., 2012; Creech et al., 2008) that HME should prepare students for performative musical outcomes, while also developing their entrepreneurial professionalism (Dent et al., 2016) whereby they are equipped to manage their own livelihoods.

In response to this need, a number of UK, European, and Australian HME institutions have designed and incorporated music business and industry courses to help students acquire the business acumen required for entrepreneurship and career management. These courses typically include topics such as self-management and promotion, networking, financial management, and grant writing (Tolmie, 2013). Work integrated learning (WIL) opportunities and internship programmes are also gaining popularity as a means to providing industry experience to students in a variety of settings.

While these topics and opportunities provide relevant knowledge and experiences through which to develop career skills, Bartleet and Carfoot (2014) argue that musicians ideally also need to connect music to "broader agendas, such as social justice and an ethics of care". Further to this, Crossick (2018), a renowned HME and policy expert, argues for the fostering of community and cultural engagement and for using music for social purposes, such as health, rehabilitation, and criminal justice. As Grant (2018) explains,

When a tertiary curriculum offers students opportunities to develop their social, moral, and ethical values alongside disciplinary knowledge and skills, students more readily grasp the potential usefulness of their learning. They are empowered and mobilised to put their knowledge and skills to the benefit of people's lives, including their own. They become a force for social good.

The concept of professionalism, therefore, arguably needs to extend beyond career management skills, to include engagement with communities in a socially responsible and ethical manner. This requires musicians, through their engagement with the arts, to learn about social responsibility, including cultural and social sensitivity, and to develop skills that enable them to contribute meaningfully to the communities in which they move (Elliott, 2012; Elliott et al., 2016). Grant (2019) further argues that "a socially engaged tertiary education improves learning outcomes for students, with concomitant benefits for universities and society at large" (p. 388). HME institutions are consequently realising the urgency of embedding opportunities for social responsibility and engagement within their programmes.

A number of HME institutions have developed Bachelor of Community Music degrees (e.g. Wilfrid Laurier University, Canada; University of Sunderland, UK), which focus on community outreach and community music teaching skills. Others 
are embedding within existing Bachelor of Music degrees, courses, or community engagement opportunities, which may include collaborative performance projects or community outreach experiences. While not diminishing the importance of traditional courses such as music history and theory, the above community engagement experiences place learning within a broader social context, requiring students to increase their interpersonal and intercultural understanding (Bartleet et al., 2012). This type of learning potentially has a profound effect on the development of society. As Mockler (2005) argues, "the best and most important teaching is that which sees its aim as the transformation of society through the contribution it makes to the formation of human beings who think critically, act ethically and seek justice through their lives" (p. 733). Thus, HME institutions may begin to recognise the need to develop in students professionalism that extends beyond discipline-specific knowledge and skills that include those that are more transformative (Sachs, 2003).

Transformative professionalism (Sachs, 2003) is grounded in Mezirow's (2003) conceptualisation of transformative learning, which emphasises the need to think, reflect, and engage critically to enhance one's ability to develop and learn autonomously and collaboratively in meaningful ways (Carey, et al., 2017). While this term was originally coined in relation to teacher professional development, its fundamental values reflect the changing nature of graduate needs and are therefore relevant to discuss in relation to developing professionalism within a HME context.

\section{Developing transformative professionalism}

The fundamental values within Sach's (2003) conception of transformative professionalism, which are discussed in more detail below, include learning; participation; collaboration; cooperation; and activism.

Learning: Learning within this context refers to a "process of becoming" (Wenger, 1998, in Sachs, 2003, p. 31) that transforms who we are, what we can do and where we place our focus. In this way, transformative professionalism involves ongoing renewal of practice through lifelong learning, requiring the ability to think and reflect critically (Mezirow, 2009). Equipping students with the skills, attributes, and mindsets required for such critical insight is key to developing their capacity for transformative professionalism.

Participation: Transformative professionalism supports individuals to develop as "active agents" (Sachs, 2003, p. 32) who participate fully and openly with the communities in which they operate. Transforming how people relate to one another requires challenging the hierarchical structures that traditionally restrict autonomy and impede the creation of the culture of support fundamental to transformative professionalism.

Collaboration: Collaboration extends participation to include joint decisionmaking. Sachs (2003) cautions that this requires "time, careful negotiation, trust and effective communication" (p. 32), which are all skills that can be 
cultivated. Such collaboration has the ability to result in mutual learning and transformation of all involved.

Cooperation: Cooperation, whereby learning from and with one another results in collective expertise, facilitates the development of the trust required for collaboration. This places learning from and with one another at the centre of transformative professionalism. Crucial to the development of each of these values are openness, flexibility, reliability, resilience, and adaptability, which in turn enhance joint decision-making, critical thinking and reflection, problem-solving, effective communication and interpretation of contexts and consequences (Baxter \& King, 2004).

Activism: The final value for transformative professionalism is activism, which empowers people to become change agents with social or moral advocacy at their core. Here, the skills and attributes outlined in the other four values are channelled into community engagement or social responsibility with the aim of contributing to positive social change.

As Sachs (2003) explains, while these values may individually not result in transformative professionalism, "Taken together these specify what it means to be a socially responsible and active professional for the new millennium" ( $p$. 30). Forming the foundation for transformative professionalism, these values empower individuals to be active and engaged practitioners who use their craftin this case music - to contribute meaningfully to the communities in which they work.

For HME, developing transformative professionalism thus requires going beyond consideration of what course content and discipline-specific knowledge and skills are taught (though this is certainly one aspect) to focusing on how curricula are delivered and the opportunities and learning environments cultivated to support students in developing transformative professionalism.

\section{Transformative pedagogies}

Transformative pedagogy is an effective approach to developing how skills and principles are embedded in transformative professionalism. It focuses on engaging students in the learning process, thereby developing autonomy and ownership of learning (Carey et al., 2013). With a focus on active student participation, student-teacher and student-student collaboration and cooperation, aligning with the above values, transformative pedagogy encourages students to draw on their prior knowledge, examine arguments logically and critically, and to monitor their own progress as they learn (Entwistle, 2009). Researchers and pedagogues have asserted that this focus on the learning process, as opposed to discipline-specific knowledge acquisition alone, enhances student agency, cognitive maturity, and flexibility (Biggs, 2011; Carey et al., 2013; Gaunt \& Westerlund, 2016). The focus on ways of being, knowing, and interacting also prepares students to participate meaningfully within various social contexts, contributing to creating positive social change through activism. 
Transformative pedagogy also removes traditional restrictions over where learning occurs, and challenges the typical teacher-student hierarchies found in formal education contexts, by placing the student experience at the heart of learning activities. Recognising the role that experiential learning (Kolb, 1984) plays in stimulating critical reflection and action, teachers utilising transformative pedagogy seek authentic learning environments that connect students to real-life scenarios and provide a platform for students to engage, reflect, and transform through participating and collaborating with others (Wiggins \& McTighe, 2005). This student-led active learning approach thus aims to cultivate transformative professionalism in students.

While employing a transformative pedagogical approach within individual courses is the responsibility of individual teachers, in order for graduates to be knowledgeable, skilled, and ethically and socially informed, a holistic program approach is required. Such an approach requires the creation of extended learning opportunities that enhance, rather than dilute, students' performative music learning outcomes. Through embedding ways of knowing and being into a range of contexts and opportunities presented in courses across a Bachelor of Music degree in a guided and cumulative manner, such an approach may enhance students' ability to apply the skills and knowledge learned within a contemporary society.

The following case explores one Australian conservatoire's attempt to realise this objective.

\section{Case: Queensland Conservatorium Griffith University}

Griffith University is an innovative university in Brisbane, Queensland, Australia that values progressive approaches to education. From its inception in 1971, Griffith University has acknowledged that professional environments and requirements constantly evolve, and that universities need to "equip their students to adapt and lead positive change for the future" (Griffith University Academic Plan, n.d.). More recently, its 2020 agenda places "students and innovative teaching and learning practices at the core of [its] activities" (Griffith University Strategic Plan). The university at large acknowledges the expanding professionalism expectations of all industries and the need to actively engage students in educational experiences that promote social responsibility and an ability to adapt. Its core commitment is to provide dynamic, challenging, and stimulating learning environments that enable students to realise their potential through actively transforming and creating their own futures. As outlined in the Graduate Attributes, Griffith University aspires to produce graduates who are knowledgeable and skilled, with critical judgement; effective communicators and collaborators; innovative, creative, and entrepreneurial; socially responsible and engaged in their communities; and effective in culturally diverse and international environments.

The Queensland Conservatorium Griffith University (QCGU) is one school within Griffith University with an enrolment of approximately 600 undergraduate students across three majors: Performance; Popular Music and Creative Music 
Technologies. The mission of QCGU is to explore holistic ways of supporting emerging musicians and cultivating the skills required for 21 st century transformative professionalism, with the primary aim of ensuring "graduates are highly skilled, musically adaptable and equipped to enter professional life as a creative and flexible twenty-first century musician”. This mission requires a commitment to regularly researching, reviewing, and refining degrees offered to ensure they consistently and continually reflect the needs of the broader field.

QCGU undergoes regular reviews through which formal feedback from a range of stakeholders, including students, staff and the Industry Advisory Board, and informal feedback from relevant organisations and committee board members, is provided (for a history of QCGU's reviews and outcomes, see Carey \& Lebler, 2012) to ensure they remain relevant and evolve according to the changing needs of graduates. Internally there are also rigorous processes of curriculum and pedagogy renewal with each iteration of its courses. Through the reviewing, planning, and implementation process, convenors and educators have access to curriculum design consultants and a range of professional development workshops aimed at enhancing pedagogical practices and course design. These are offered through the GU Learning Futures department, whose role in part is to support educators and students to innovate using evidence-based collaborative practices.

In a recent (2017) internal audit of the three-year Bachelor of Music degree, course offerings were reviewed to ensure they aligned strongly with the aims of the degree. Through this process, an international benchmarking exercise, led by the Deputy Director (Learning \& Teaching) was undertaken to assess how course offerings at QCGU compared with other renowned international universities. It is evident that there is not one uniform structure to a Bachelor of Music, with other institutions also currently revising and broadening the scope of their course offerings to reflect 21 st century demands. Recently, for example, the music department at Harvard University made a "radical departure from [their] previous very strict, defined, and academic curriculum, which was based heavily in theory and musicology" (Tilton, in Leifer, 2017, para. 12). Their aim is to prepare students for continued learning beyond their degree by focusing on the learning process (Robin, 2017).

Each Bachelor of Music degree analysed during the audit featured varying mandatory requirements in relation to performance, history, music theory, and aural courses, as well as different combinations of non-mandatory courses. Some degrees integrate entrepreneurial and/or community engagement courses; others do not. With this apparent flexibility in framework and approach, the review process provided an opportunity to rethink QGCU's traditional degree structure. Through research, extensive consultation with Heads of Area, course convenors, faculty colleagues, student feedback, and other stakeholders over time, there was a general consensus that there was an opportunity and need to embed further transformative learning experiences into the degree through community engagement and professional practice. This led to a reconfiguration of compulsory credit points required for music literature and theory/aural for completion of a music degree, with $25 \%$ of compulsory credit points dedicated to electives. Through 
this process, it was important to ensure learning objectives and outcomes of the Bachelor of Music were not compromised, and were indeed strengthened by any changes made. It also led to a purposeful development of transformative professionalism through four broad categories of courses: performance practice; music literature/research; mobility degrees; and professional practice.

\section{Performance practice}

During their degree (with the exception of Creative Music Technologies majors), all students enrol in performance study, which typically involves a weekly oneto-one lesson and/or ensemble studies and performance workshops. While traditionally the master-apprentice one-to-one lineage portrays students as passive recipients of their teacher's knowledge and instruction, a transformative pedagogical approach recognises one-to-one lessons as an opportunity to cultivate students as independent, autonomous learners (Carey et al., 2017; Carey \& Coutts, 2019; Coutts, 2019; Smilde, 2018). While acknowledging that developing musical and technical ability is central to performance practice, it is also vital to foster students' autonomy and their higher order thinking skills through reflective practices (Carey \& Coutts, 2019). Through adopting a transformative pedagogical approach to lessons and workshops, the aim is to increase autonomy, critical thinking, and reflection (Carey et al., 2013), which, as Glazer, Abbott and Harris (2004) explain, contribute to professional growth.

One of the ways in which QCGU students are required to engage in a reflective process is through documenting their performance learning in a Performance Studies Portfolio (PSP) or journal in the first year of their studies. The aim of the PSP is to "capture reflection on a range of student activities and experiences associated with their performance studies" (Carey et al., 2017, p. 102), in order to develop agency and the capacity to problem solve through guided critical reflection tasks. Recognising the need to cultivate a collaborative and supportive learning culture, these tasks first require students to participate in musical and peer review activities and to reflect on their experiences and the guidance and feedback received. This collaborative and reflective approach to learning exemplifies the culture of transformative professionalism, and works to break down the traditionally competitive culture typified in conservatoires globally (Gaunt \& Westerlund, 2016). This peer support is central to collaboration and cooperation (Sachs, 2003), and, as Mezirow (2003) argues, reflection is at the heart of meaning making, intentional learning, and problem-solving. Taken together, this approach is inte-

gral to preparing 21 st-century students to become agile learners both throughout and beyond their degree.

While the PSP aims to offer support through guided questions within the journals, students also attend a seminar during the first week of their academic year, which introduces them to the notion and understanding of reflective practice and its process. Although the depth of responses in this process inevitably varies between students, PSPs have been found to develop student autonomy, increase shared responsibility through encouraging peer problem-solving, and to increase 
clarity and confidence in student learning through goal-setting and discussions with their teachers (Carey et al., 2017).

In addition to standard performance opportunities through concert programmes and recitals, students in second and third year are provided with opportunities to utilise their performance skills within a range of community settings. Engaging with communities in settings such as children's hospitals, nursing homes, and schools through projects and/or elective courses increases students' awareness of contexts where their music-making may be of value and can lead to developing activist values. As Luce (2001) explains, these kinds of activities enable students to "translate how others make sense of themselves and their role in the world into a new, socially constructed knowledge-based community" (p. 21). H. J. Minors and colleagues (2017) describe this as "critical artistry ... whereby students develop new insights and skills that are critically understood within the context of their new experiences, to develop artistic maturity and embrace challenge" (p. 462). They argue that this "in turn promotes their own artistic identity through continual applied practice" (p. 462), as well as developing resilience and the capacity to lead through innovation.

Reciprocity is also integral to connecting with communities through music. For example, in the children's hospital context, students learn to engage with, and respond to, patients, parents, nurses, and other hospital staff, which in turn develops empathy and authentic ways to connect with audiences. Through engaging with communities through their artistic practices, students are working with the audiences rather than for them. This provides transformative learning experiences underpinned by participation, collaboration, and cooperation, and develops skills and attributes that would be much less likely to develop in traditional performance contexts.

Individual instrumental lessons, peer activities partnered with reflective journaling, and authentic community music engagement are three very different but complementary learning experiences offered to students at QCGU to foster the development of transformative professionalism in relation to their musicianship. In each learning context, students and teachers alike are required to challenge traditional learning settings and hierarchies, to focus on collaboration, participation, and active and authentic learning, and, in doing so, to expand their focus beyond the development of musical skills.

\section{Music literature courses}

While situated learning in the form of community-based performance opportunities contributes to the development of social awareness and collaboration skills, classroom-based courses also prepare students to engage in a variety of contexts. By developing academic and research skills that enable students to understand and reflect on information through a range of perspectives, QCGU music literature courses encourage students to connect contextual and societal information to their practice as musicians. Using disciplinary knowledge and skills gained through research-based learning may also help students to develop creative, innovative, 
and entrepreneurial approaches to professionalism. While a diverse range of music literature courses, underpinned by a strong research orientation, have always been embedded in the QCGU curriculum, more recently these have been reconsidered to include those that focus on exploring the function of music within a variety of contemporary societal contexts and musicians' roles in informing and contributing to social change.

The first of these courses, Exploring Music, aims to introduce students to the impact of contemporary issues (including the political, social, cultural, economic, and technological) on music in today's Australian society. It brings together a diverse cohort-including instrumental, vocal, jazz, classical, opera, popular music, music technology, and composition students - and therefore requires an inclusive pedagogical approach to engage students with their learning. Through sharing their experiences and perceptions of different musical styles and issues with their peers, students are encouraged to become aware of their musical, cultural, and social biases and to consider alternate perspectives. As Mezirow (2003) explains, this can lead to transformation of assumptions and increased curiosity, leading to greater engagement with learning.

Two further literature courses, Music \& Society and Music Across Cultures, are electives that build on Exploring Music. They offer global perspectives on the diverse roles of music and music-making in human societies and cultures, and challenge assumptions about the very nature of music and the role it can play in social change. The courses encourage students to explore social issues of personal interest, highlighting musicians' responsibilities in advocating for and creating social change, developing the activist lens of transformative professionalism. Students are also provided with opportunities to hear the experiences of, and create music with, musicians from non-Western backgrounds (see Grant \& Learning Futures, 2018, for an example), with interactions being facilitated by the lecturer to ensure appropriate cultural sensitivity is employed throughout the exchange (Elliott, 2012).

\section{Mobility programmes}

QCGU students are afforded several practice-based, situated learning opportunities through a Global Local Music Project. The central aim of this project is to immerse students in a cultural context other than their own within Australia or abroad, thereby extending their cultural experiences. Through this immersive trip, students are involved in musical practices and/or practice-led music research projects that highlight a range of different environmental and social issues to their own. Students musically explore important cultural, social, and/ or political issues in the location visited, which manifests in the form of a community-led project, music performance, recording, or publication. The aim is not to simply share music with others, but through the process to reciprocally learn about self and others, to give back and to receive, to foster and nurture a sense of community and to continue to develop critical reflection and social awareness. 
One initiative within Global Local is a community service-learning programme that focuses on fostering meaningful collaborations between universities and Indigenous Australian communities (Bartleet, 2011). Participating students spend two weeks in remote Central Australia, where they work with local Indigenous people to record and write albums, manage community festivals, stage and record performances, or run school holiday programmes. The founder and leader of this initiative explains that "centrality of relationship building is crucial when working with Indigenous communities" (Bartleet, 2011, p. 20) and that mutuality and reciprocity are of prime importance (Bartleet et al., 2014). She laments that "university courses rarely venture beyond the walls of their institutions like this, and consequently students and Indigenous musicians are seldom given the opportunity to build meaningful relationships with one another" (Bartleet \& Carfoot, 2014, p. 131).

Such opportunities are an important aspect of students' professional development, as they foster connections between theory and practice, cognitive and affective learning, and colleges and communities (Butin, 2006). Bartleet and Carfoot (2014) argue these experiences change how students operate as artists, replacing the inherent competitiveness of the industry with openness and reciprocity. This fosters in students an "ethic of care" (Lines, 2018, p. 392), whereby experiences not only develop technical skills, performance, and rehearsal approaches, but also cultivate new ideas and create connections that are socially, culturally, and ethically strong. This has "immense transformational potential as a sustained, immersive, and consequential pedagogical practice" (Butin, 2006, p. 474).

A further mobility opportunity presented to students is an immersion trip that focuses on developing students' capacity to engage meaningfully with specific cultural destinations in Australia, the Asia Pacific, or abroad. The convenor, Dr Catherine Grant, argues that this extends beyond learning about different societies and cultures, and "demands an ability to be reflexive, to apprehend and understand one's own self and society and culture in relation to those 'others" (Grant, 2017 , p. 7), aligning strongly with transformative professionalism, and exemplifying how each of the first four values (learning, participation, collaboration, and cooperation) culminate in activism. In investigating students' experiences, Grant (2017) found this opportunity contributed to: the development of students' global awareness and understanding; a growing understanding of self and their societies; and a cultivated sense of social responsibility. Specifically, her research revealed that students became aware of their own privilege, of social injustice such as poverty and gender inequalities, and issues of human rights and the complexities involved through factors such as education and politics.

The trip also "provoked their deep consideration of their own personal and professional roles and responsibilities, present and future, local and global" (Grant, 2017 , p. 9). This paradigm shift in the potential for their own musical and professional goals and identity led students to become aware of and experience new contexts through which to engage with other musicians, to reach and interact with different audiences, such as school children and local communities, and start to consider what musical career paths might be open to them of which they were previously unaware. 
The suite of music literature courses and mobility opportunities discussed above place music as a change agent and as an expression of cultural and social identity. As Grant (2019) explains, such learning not only cultivates the values, attitudes, and skills needed to foster social engagement and responsibility, but also provides students with "the best chances of forging meaningful, socially engaged lives during and after their studies - and more than this, of being 'empowered and critically reflective about current society so that they may not only live in it, but transform it"” (Whyte, 2009, p. 319).

\section{Professional practice}

In acknowledging that musicians are often required to self-manage, self-promote, and create their own performance, teaching, and other opportunities, QCGU offers a suite of three progressive (sequenced) courses, titled My Life as a Musician (MLaaM) as well as pedagogy courses and musicians' health. These courses focus on a range of topics relating to entrepreneurial professionalism to assist students to develop and manage a portfolio career (see Tolmie, 2017). Topics include career identity and understanding of self; professional conduct; effective time management; current affairs and arts policy; leadership; and human resource management.

In parallel with these courses, students have the opportunity to select from an extensive range of electives that align with their career aspirations, including further courses in performance, music literature/history, music theory/aural, composition, music technology, instrumental or vocal pedagogy, and individual research and performance projects. Combined, the courses students complete throughout their Bachelor of Music enable them to develop deep music skills while also developing their transformative professionalism, equipping them with the skills to be socially engaged and responsible while developing their career pathways.

\section{Professional development of academic staff}

Just as students require support to build their transformative professionalism, one of the constant challenges for HME institutions is to ensure that teachers are provided with support and development opportunities necessary to deliver innovative curricula design. While teachers are experts in their field-and this expertise is

Table 4.1 Overview of selected core Bachelor of Music courses at QCGU

\begin{tabular}{|c|c|c|c|c|}
\hline \multicolumn{2}{|l|}{ Performance } & \multicolumn{2}{|c|}{ Music literature/mobility } & \multirow{2}{*}{$\begin{array}{l}\text { Professional practise } \\
\text { My Life as a Musician }\end{array}$} \\
\hline $\begin{array}{l}\text { One-to-one } \\
\text { lessons }\end{array}$ & Workshops & Exploring I & Music & \\
\hline $\begin{array}{l}\text { Concert } \\
\text { programmes }\end{array}$ & Recitals & $\begin{array}{l}\text { Music and } \\
\text { Society }\end{array}$ & $\begin{array}{l}\text { Music Across } \\
\text { Cultures }\end{array}$ & $\begin{array}{l}\text { Pedagogy/Musicians' } \\
\text { Health }\end{array}$ \\
\hline $\begin{array}{l}\text { Community outre } \\
\text { performances }\end{array}$ & each & $\begin{array}{l}\text { Project } \\
\text { study }\end{array}$ & $\begin{array}{l}\text { Global Local } \\
\text { mobility project }\end{array}$ & Internships \\
\hline
\end{tabular}


something to draw on and celebrate - it is recognised that learning and teaching is an ever-evolving field and that the non-musical attributes and skills students need are changing. It is thus vital for institutions and teachers to continually reflect on and adapt pedagogical approaches to ensure they align with the needs of graduates and are underpinned by pedagogical theory and scholarship (Mausethagen $\&$ Smeby, 2016) and the values of transformative professionalism (Sachs, 2003; Mockler, 2005).

As with pedagogy, there is also a need to shift from traditional professional development opportunities to those that are more transformative (Sachs, 2003). As Avis (2005) argues, this is because traditional approaches to professional development, which focus on performativity and accountability to external results, tend to "stifle innovation and encourage deeply conservative practices" (p. 213). Furthermore, such opportunities are often perceived as evaluative (Bell \& Mladenovic, 2008) or undermining professional autonomy (Gosling, 2002), most often resulting in low engagement and preventing many teachers from taking responsibility for their own professional growth (Glazer et al., 2004). Thus, effective professional development opportunities are those that are transformative; that require teachers to be proactive and responsible; that embrace learning, participation, collaboration, and cooperation; that focus on student engagement and learning, and risk-taking by both the teacher and the students; and which, extending to activism, advocate for and create positive changes within teaching practices (Sachs, 2003). In this way, innovation builds from the foundations, rather than being imposed from the top, and fosters the same skill set and approaches to professional growth that teachers aim to cultivate in students.

Transformative professional development requires the support of university leadership in cultivating a trusting and safe environment, which encourages teaching staff to step out of their comfort zones and to question their practices in collaboration with others. Mockler (2005) describes this as "courageous leadership", which on both school and system levels not only tolerates risk-taking but embraces it as a path to authentic relationships, critical and innovative practice, and ongoing growth and transformation. QCGU therefore provides opportunities for teachers to collaboratively share their teaching expertise and professional practice with their peers, and, through reflective discussions, to develop deeper awareness and insights into their practice (Carey et al., 2018; Burwell et al., 2017). These opportunities range from initiatives such as peer-to-peer collaborations and workshops, to larger events such as symposia and professional development retreats.

Given the importance of personal autonomy and self-responsibility for effective engagement, it has been important to ensure that participation in collaborative opportunities provided is voluntary. While this has meant that not all teachers have engaged, it is acknowledged that creating shifts in culture takes time. Increasing teacher participation in professional development has required a commitment on behalf of leadership to provide ongoing opportunities, encouragement, and support through the creation of space, resources, and acknowledgement of time in teachers' workloads, and this has led to growth in engagement. 
Since its inception in 2011, many colleagues involved in professional development activities have become advocates for the activities through their own positive experiences and growth. Likewise, teachers are gradually becoming more comfortable in sharing their practices and exploring different teaching models as a result. Positive feedback from participating staff has indicated benefits, including gaining a heightened awareness of their current teaching practices; discovering new pedagogical insights to inform their future teaching; increasing their awareness of teaching methodologies; discussing teaching strategies with peers; breaking down feelings of professional isolation; finding new solutions to challenges faced; and putting the needs of the student first (Carey et al., 2018).

Ultimately, transformative professionalism - the ability to think, reflect, and act critically, to engage deliberately and contribute meaningfully with an ethic of care, and to be willing and able to adapt to and create positive change - needs to be fostered at all levels, from students to teachers to leadership. Arguably, without this synergy, it will be more difficult, if not impossible to achieve.

\section{Closing thoughts}

This chapter has provided an outline of one university's response to developing music students' transformative professionalism within its Bachelor of Music degree. While not necessarily a blueprint, transformative approaches to learning and teaching within HME go some way towards developing students' professionalism and ensuring that music graduates are equipped with the ability to manage their own livelihoods and to meaningfully contribute to society.

The approach outlined highlights a shift in focus from discipline-specific knowledge and skill acquisition only, to developing students' social responsibility, leadership, and entrepreneurial capabilities. Through reflective practice opportunities, situated community learning experiences, and engagement in class activities and discussions, students are challenged to expand their understanding of global topics. Furthermore, they are equipped with a set of transferable skills and attributes that enable them to be adaptable and resilient problem-solvers as they navigate their world beyond graduation.

In order for QCGU's commitment to developing students' professionalism to be effective, it is essential to continually reflect on programme offerings, adapting as necessary to ensure they align with the latest research and scholarship. It is also imperative that educators are open to developing their teaching practices, exploring transformative pedagogical approaches, and adapting in accordance with the changing 21st-century HME landscape and to develop their own transformative professionalism. To this end, the case highlights the need to provide professional development opportunities that encourage and empower teachers to collaborate, share their practices, take risks, and innovate within their classes.

While the courses within the Bachelor of Music at QCGU are likely to change over time, by adherence to the fundamental principles of continuous and critical review of curriculum design, research-informed courses, and professional 
development for educators, QCGU can at least ensure that changes continue to be informed, deliberate, and in service of students' needs.

\section{References}

Avis, J. (2005). Beyond performativity: Reflections on activist professionalism and the labour process in further education. Journal of Education Policy, 20(2), 209-222. doi:10.1080/0268093052000341403

Bartleet, B. L. (2011). Stories of reconciliation: Building cross-cultural collaborations between Indigenous musicians and undergraduate music students in Tennant Creek. Australian Journal of Music Education, 2, 11-21. Retrieved from https://search .informit.com.au/documentSummary; $\mathrm{dn}=756251699414788$;res=IELHSS

Bartleet, B. L., Bennett, D., Bridgstock, R., Draper, P., Harrison, S., \& Schippers, H. (2012). Preparing for portfolio careers in Australian music: Setting a research agenda. Australian Journal of Music Education, 1, 32-41. Retrieved from https://eric.ed.gov/?id=EJ1000243

Bartleet, B. L., Bennett, D., Marsh, K., Power, A., \& Sunderland, N. (2014). Reconciliation and transformation through mutual learning: Outlining a framework for arts-based service learning with Indigenous communities in Australia. International Journal of Education and the Arts, 15(8), 1-23. Retrieved from http://www.ijea.org/v15n8/.

Bartleet, B. L., \& Carfoot, G. (2014). Desert harmony: Stories of collaboration between Indigenous musicians and university students. International Education Journal: Comparative Perspectives, 12(1), 180-196. Retrieved from https://openjournals.library .sydney.edu.au/index.php/IEJ/article/download/7445/7801

Baxter, M. B. B., \& King, P. M. (2004). Learning Partnerships: Theory and Models of Practice to Educate for Self-Authorship. Stylus.

Bell, A., \& Mladenovic, R. (2008). The benefits of peer observation of teaching for tutor development. Higher Education, 55(6), 735-752. Doi:10.1007/s10734-00790931

Bennett, D. (2019). Higher education and the need to educate the whole musician: Musicians' work in early-, mid- and late-career. Proceedings for the $22^{\text {nd }}$ Commission for the Education of the Professional Musician: The Musicians' Career Lifespan. July 11-13, 2018, Almaty, Kazakhstan.

Bennett, D., Richardson, S., \& Mackinnon, P. (2015). Enacting Strategies for Graduate Employability: How Universities Can Best Support Students to Develop Generic Skill. Australian Government, Office for Learning and Teaching, Department of Education and Training.

Biggs, J. B. (2011). Teaching for Quality Learning at University: What the Student Does. Open University Press.

Bridgstock, R., \& Hearn, G. (2012). A conceptual model of capability learning for the twenty-first century knowledge economy. In D. Rooney, G. Hearn, \& T. Kastelle. (Eds.), Handbook on the Knowledge Economy (pp. 105-122). Edward Elgar.

Burwell, K., Carey, G., \& Bennett, D. (2017). Isolation in the music studio: The secret garden. Arts and Humanities in Higher Education, 18(4), 372-394.

Butin, D. W. (2006). The limits of service-learning in higher education. The Review of Higher Education, 29(4), 473-498. Retrieved from https://muse.jhu.edu/article/198714/pdf

Carey, G., Bridgstock, R., Taylor, P., McWilliam, E., \& Grant, C. (2013). Characterising one-to-one conservatoire teaching: Some implications of a quantitative analysis. Music Education Research, 15(3), 357-368. 
Carey, G., \& Coutts, L. (2019). Preparing students for effective and autonomous learning through a transformative critical response process. Proceedings for the $22^{\text {nd }}$ Commission for the Education of the Professional Musician: The Musicians' Career Lifespan. July 11-13, 2018, Almaty, Kazakhstan.

Carey, G., Coutts, L., Grant, C., Harrison, S., \& Dwyer, R. (2018). Enhancing learning and teaching in the tertiary music studio through reflection and collaboration. Music Education Research, 20(4), 399-411. https://doi.org/10.1080/14613808.2017.1409204

Carey, G. Harrison, S., \& Dwyer, R. (2017). Encouraging reflective practice in conservatoire students: A pathway to autonomous learning? Music Education Research, 19(1), 99110. https://doi.org/10.1080/14613808.2016.1238060

Carey, G., \& Lebler, D. (2012). Reforming a bachelor of music programme: A case study. InternationalJournalofMusicEducation,30(4),312-327.doi:10.1177/0255761412459160

Creech, A., Papageorgi, I., Duffy, C., Morton, F., Haddon., E., Potter, J., de Bezenac, C., Whyton, T., Himonides, E., \& Welch, G. (2008). From music student to professional: The process of transition. British Journal of Music Education, 25(3), 315-331. https:// doi.org/10.1017/S0265051708008127

Crossick, G. (2018). Arts, Citizenship and Civil Society. Keynote Address, Reflective Conservatoire Conference: Artists as Citizens. Guildhall School of Music, London.

Coutts, L. (2019). Exploring partnerships: A students as partners pedagogical approach for fostering student engagement within an academic music course. Proceedings for the $22^{\text {nd }}$ Commission for the Education of the Professional Musician: The Musicians' Career Lifespan. July 11-13, 2018, Almaty, Kazakhstan.

Dent, M., Bourgeault, I. L., Denis, J.-L., \& Kuhlmann, E. (2016). Introduction. In M. Dent, I. L. Bourgeault., J.-L. Denis, \& E. Kuhlmann (Eds.), The Routledge Companion to the Professions and Professionalism (pp. 1-11). Routledge.

Elliott, D. J (2012). Another perspective: Music education as/for artistic citizenship. Music Educators Journal, 99(1), 21-27. https://doi.org/10.1177/0027432112452999

Elliott, D. J., Silverman, M., \& Bowman, W. D. (2016). Artistic citizenship: Introduction, aims, and overview. In D. J. Elliot, M. Silverman, \& W. D. Bowman (Eds.), Artistic Citizenship Artistry, Social Responsibility, and Ethical Praxis (pp. 3-21). Oxford University Press.

Entwistle, N. J. (2009). Teaching for Understanding at University: Deep Approaches and Distinctive Ways of Thinking. Palgrave Macmillan.

Gaunt, H., \& Westerlund, H. (2016). Collaborative Learning in Higher Music Education. Routledge.

Glazer, C., Abbott, L., \& Harris, J. (2004). A teacher-developed process for collaborative professional reflection. Reflective Practice, 5(1), 33-46. https://doi.org/10.1080 /1462394032000169947

Gosling, D. (2002). Models of peer observation of teaching. Generic Centre: Learning and Teaching Support Network, 8(10). Retrieved from https://www.researchgate.net/profile /David_Gosling/publication/267687499_Models_of_Peer_Observation_of_Teaching/ links/545b64810cf249070a7955d3.pdf

Grant, C. (2017). Developing global citizenship in tertiary performing arts students through short-term mobility programs. International Journal for Education and the Arts, 19(15), 1-25. https://doi.org/10.18113/P8ijea1915

Grant, C. (2019). What does it mean for a musician to be socially engaged? How undergraduate music students perceive their possible social roles as musicians. Music Education Research, 21(4), 387-398. https://doi.org/10.1080/14613808.2019 .1626360 
Grant, C., \& Learning Futures. (2018). Creative Collaboration With Migrant and Refugee People to Build Intercultural Capabilities in Music Students. Retrieved from https://app .secure.griffith.edu.au/exlnt/entry/6805/view

Griffith University (n.d.). Griffith Academic Plan 2017-2020. Retrieved from https://www .griffith.edu.au/_data/assets/pdf_file/0033/169872/academic-plan1.pdf

Griffith University (n.d.). Griffith Strategic Plan 2018-2019. Retrieved from https://www .griffith.edu.au/_data/assets/pdf_file/0029/186572/2018-2019-Strategic-Plan.pdf

Kolb, D. (1984). Experiential Learning: Experience as the Source of Learning and Development. Prentice Hall.

Leifer, V. P. (2017, March 22). Music department to adopt new curriculum beginning Fall 2017 [web log post]. Retrieved from www.thecrimson.com

Lines, D. (2018). The ethics of community music. In B. Bartleet \& L. Higgins (Eds.), The Oxford Handbook of Community Music (pp. 385-402). Oxford University Press.

Luce, D. W. (2001). Collaborative learning in music education: A review of the literature. Update: Applications of Research in Music Education, 19(2), 20-25. https://doi.org/10 $.1177 / 87551233010190020105$

Mausethagen, S., \& Smeby, J. C. (2016). Contemporary education policy and teacher professionalism. In M. Dent, I. L. Bourgeault, J. L. Denis, \& E. Kuhlmann (Eds.), The Routledge Companion to the Professions and Professionalism (pp. 329-342). Routledge.

Mezirow, J. (2003). Transformative learning as discourse. Journal of Transformative Education, 1(1), 58-63. doi:10.1177/1541344603252172

Mezirow, J. (2009). An overview on transformative learning. In K. Illeris (Ed.), Contemporary Theories of Learning (pp. 90-105. Routledge.

Minors, H. J., Burnard, P. Wiffen, C., Shihabi, Z., \& van der Walt, J. S. (2017). Mapping trends and framing issues in higher music education: Changing minds/changing practices. London Review of Education, 15(3), 457-473. https://doi.org/10.18546/LRE .15.3.09

Mockler, N. (2005). Trans/forming teachers: New professional learning and transformative teacher professionalism. Journal of In-Service Education, 31(4), 733-746.

Robin, W. (2017). What controversial changes at Harvard mean for music in the university. [web log post]. Retrieved from https://nationalsawdust.org/thelog/

Sachs, J. (2003). The Activist Teaching Profession. Open University Press.

Smilde, R. (2018). Community engagement and lifelong learning. In B.-L. Bartleet \& L. Higgins (Eds.), The Oxford Handbook of Community Music. Oxford University Press. doi:10.1093/oxfordhb/9780190219505.013.32

Tolmie, D. (2013). Designing a Tertiary Music Institution Course to Create Industryready Graduates. The CALTN Papers: The refereed proceedings of the Creative Arts Learning and Teaching Network symposium, Hobart, Australia.

Tolmie, D. (2014). Identifying, analysing and aligning "the dream" with vocational preparation: An investigation into first-year music undergraduate career aspirations and motivations. Proceedings for the $20^{\text {th }}$ Commission for the Education of the Professional Musician: Relevance and Reform in the Education of Professional Musicians (pp. 73-85).

Tolmie, D. (2017). My Life as a Musician: Designing a Vocation Preparation Strand to Create Industry Prepared Musicians. (Doctor of Philosophy), Griffith University, Brisbane, Australia.

Whyte, B. (2009). The heart of the matter: A pre-service teacher's narrative on coming to a social justice oriented vision for music education. In E. Gould., J. Countryman, C. 


\section{Gemma Carey and Leah Coutts}

Morton, \& L. S. Rose (Eds.), Exploring Social Justice: How Music Education Might Matter (pp. 317-324). Canadian Music Educators' Association.

Wiggins, G., \& McTighe, J. (2005). Understanding by Design. Association for Supervision and Curriculum Development.

Willingham, L., \& Carruthers, G. (2018). Community music in higher education. In B.L. Bartleet \& L. Higgins (Eds.), The Oxford Handbook of Community Music. Oxford University Press. doi:10.1093/oxfordhb/9780190219505.013.32 